\title{
COBERTURAS VEGETAIS NO DESENVOLVIMENTO VEGETATIVO DE PLANTAS DE PESSEGUEIRO ${ }^{1}$
}

\author{
LEO RUFATO ${ }^{2}$, ANDREADE ROSSI RUFATO $^{4}$, AIKE ANNELIESE. KRETZSCHMAR $^{2}$,LUCIANO PICOLOTTO ${ }^{3}$, \\ JOSÉCARLOS FACHINELLO
}

RESUMO - A utilização de cultivos de cobertura em pomares de pessegueiro no Brasil ainda é pouco difundida, apesar de haver diversas espécies de cobertura vegetal com potencial para tanto. Neste trabalho, estudaram-se os efeitos da a utilização de cinco espécies de plantas para cobertura vegetal de inverno: aveia-preta, chícharo, ervilha forrageira; nabo forrageiro; tremoço-azul, quatro consorciações entre elas e mais a testemunha, com vegetação espontânea sobre o desenvolvimento vegetativo de plantas de pessegueiro cv. Maciel sobre capedeboscq. Todas as espécies vegetais avaliadas adaptaram-se como cobertura vegetal nas condições edafoclimáticas da região Sul do Rio Grande do Sul. As coberturas vegetais, com exceção, sobretudo, do nabo forrageiro, incrementaram o desenvolvimento das plantas de pessegueiro.

Termos para indexação: Prunus persica, crescimento vegetativo, manejo do solo, pomar, cobertura vegetal.

\section{CROP COVERS IN THE VEGETATIVE DEVELOPMENT OF PEACH TREES}

\begin{abstract}
The use of the crop covers in Brazilian peach orchards is still not so spread, though there are several species of crop covers with the potential have the effect studied. This research presents the effects of the five plant species use for winter vegetal crop covers: Avena strigosa, Lathyrus sativus, Pisum sativum subesp. arvense, Raphanus sativus var. oleiferus, Lupinus angustifolius, four combinations among these species and the control treatments (native vegetation), with spontaneous vegetationon the vegetative development of "Maciel" peach tree under Capdeboscq rootstock. All of the crop covers evaluated adapted themselves to the soil and climate conditions of the south of "Rio Grande do Sul'. The crop covers, except the Raphanus sativus var. oleiferus, increased positively the phenological and vegetative development of peach trees; the Lupinus angustifolius also increased the phenological and vegetative development of plants.
\end{abstract}

Index terms: Prunus persica, vegetative development, soil manure, orchard, crop cover.

\section{INTRODUÇÃO}

Para que exista um equilíbrio efetivo entre a cultura e o ambiente, deve-se despender especial atenção à manutenção das propriedades físicas, químicas e biológicas do solo, que são base para o sucesso dos cultivos. Dentro das técnicas de cultivo empregadas atualmente, a produção integrada de frutas preconiza o equilíbrio do meio ambiente com a boa produtividade e a manutenção das propriedades biológicas do solo, pois o solo deve ser considerado um organismo vivo, em constantes modificações e não somente substrato para a sustentação física das plantas. Porém, nas Normas Técnicas Específicas para a Produção Integrada de Pêssego de 2003 - NTEPIP (FACHINELLO, et al., 2003), não está definido um sistema-padrão de cultivo do solo; no entanto, MARANGONI et al. (1995) relatam que os critérios de escolha devem ser baseados nas características climáticas e pedológicas da região, nas condições do produtor e na espécie, cultivar e porta-enxerto utilizados.

Para as condições específicas de fruteiras de caroço, no Sul do Brasil, não se dispõe de resultados científicos definitivos sobre as espécies e os procedimentos mais adequados da cobertura do solo. GIOVANNINI et al. (2001) apresentaram resultados que confirmam as vantagens da cobertura vegetal controlada em relação ao terreno descoberto e arado; observaram, também, que, com as plantas em cobertura, foi aumentada a quantidade de matéria orgânica do terreno e diminuída a lixiviação de nitratos para o subsolo. Além desses benefícios, tem a capacidade de romper camadas compactadas do solo e de melhorar a sua estrutura física, com a formação e estabilização de agregados, aumentando-se a porosidade e a aeração.

O objetivo deste trabalho foi o de verificar os efeitos de diferentes coberturas vegetais e algumas consorciações entre elas, no desenvolvimento inicial de pessegueiro.

\section{MATERIAL E MÉTODOS}

O presente trabalho foi desenvolvido em pomar de pessegueiro da cultivar Maciel enxertado sobre o porta-enxerto Capdeboscq, implantado em julho de 2000, em espaçamento de 5 x 2 metros, com as plantas conduzidas em forma de "Y", na Colônia Santo Amor, no município de Morro Redondo-RS.

Os tratamentos constaram de plantas para cobertura vegetal de inverno: aveia-preta (Avena strigosa Schreb), nabo forrageiro (Raphanus sativus L. var. oleiferus Metzg), chícharo

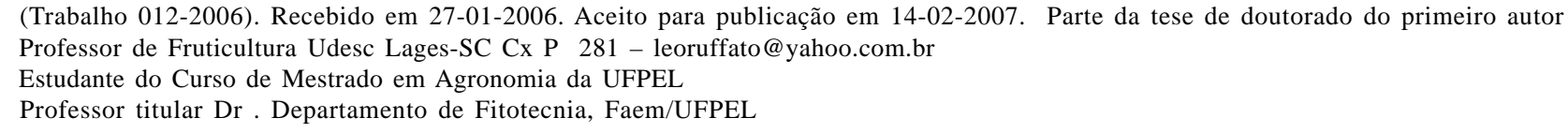


(Lathyrus sativus L.), ervilha forrageira (Pisum sativum subesp. arvense) e tremoço-azul (Lupinus angustifolius L.); de quatro consorciações entre essas espécies: aveia-preta/ervilha forrageira; aveia-preta/nabo forrageiro, aveia-preta/chícharo, nabo forrageiro/ervilha forrageira e da testemunha com vegetação espontânea composta de azevem (Lolium multiflorum Lam) no início do ciclo e capim-papuã (Brachiaria plantaginea (Link) Hitch) no final de ciclo, com delineamento experimental de blocos completamente casualizados, com 10 tratamentos, três repetições e três plantas de pessegueiro por parcela.

O cálculo da densidade de semeadura foi realizado conforme recomendações de DERPSCH \& CALEGARI (1992) em base no laudo de poder germinativo das espécies.

As coberturas vegetais de solo foram semeadas em parcelas de dimensões de 4,0 x 5,0 metros, com três plantas de pessegueiro em cada parcela. Nas bordaduras com 1 metro e uma planta de pessegueiro, entre os tratamentos, foi semeada aveiapreta .

A semeadura das coberturas vegetais foi realizada por dois ciclos agrícolas consecutivos, em 07-06-2000 e 31-06-2001. $\mathrm{O}$ manejo das coberturas vegetais foi realizado com o acamamento das plantas com grade de disco, "não-travada", no mês de novembro, nos dois ciclos agrícolas. Ao final do segundo ciclo, foram avaliados os parâmetros: diâmetro do tronco, com a medida dos diâmetros longitudinal e transversal do tronco, a $20 \mathrm{~cm}$ do nível do solo, com paquímetro digital, durante o período de repouso vegetativo; comprimento de ramos, com a medida direta de 5 ramos em cada planta; índice de fertilidade, com a relação entre comprimento de ramos e número de pares de gemas floríferas por centímetro de ramo produtivo das plantas de pessegueiro com 5 ramos amostrados por planta durante o repouso vegetativo; volume da copa, com a medida do diâmetro longitudinal (L), transversal (T) e altura $(\mathrm{H})$ da copa das plantas de pessegueiros, avaliados durante o período de repouso vegetativo das plantas, antes da intervenção de poda, calculando através da relação $\mathrm{V}=\pi ? ? \mathrm{r}^{2} . \mathrm{H} / 3$; onde $\mathrm{V}=$ volume; $\mathrm{r}=\mathrm{raio}(\mathrm{L} / 2$. T/ 2), e H=altura.

Para as coberturas vegetais, determinou-se a massa fresca e seca da parte aérea, antes do acamamento, coletou-se a parte aérea das plantas utilizadas em cobertura vegetal do solo, em 1 $\mathrm{m}^{2}$ de cada tratamento, realizando a pesagem da massa fresca, e, após secagem em estufa a $60^{\circ} \mathrm{C}$, por 36 horas, a pesagem da massa seca.

Os dados foram submetidos à análise estatística, e as médias, comparadas entre si, pelo teste de Duncan, a 5\% de probabilidade. Os dados das variáveis volume de copa e comprimento de ramo e nematóides foram submetidos à transformação de raiz quadrada de $X+0,5$ e, para a variável diâmetro do tronco, à raiz quadrada de $\mathrm{X}+1$.

\section{RESULTADOS E DISCUSSÃO}

Para as variáveis, diâmetro do tronco, volume de copa e comprimento de ramos na cultura do pessegueiro, observam-se diferenças estatísticas significativas entre os tratamentos (Tabela
1). A maior média numérica de diâmetro do tronco foi observada com a cobertura vegetal de tremoço-azul, diferindo estatisticamente apenas as de chícharo, nabo forrageiro e aveiapreta+nabo forrageiro. Quanto ao volume de copa das plantas de pessegueiro, apesar de não apresentarem diferenças estatísticas entre os tratamento, a cobertura vegetal com tremoçoazul, a aveia-preta e ervilha forrageira proporcionaram maior desenvolvimento numérico do volume de copa de pessegueiro, respectivamente.

Quando se avaliou o comprimento de ramos (Tabela 1), pôde-se observar que a cobertura vegetal com nabo forrageiro e aveia-preta + chícharo promoveram reduções significativas no comprimento dos ramos das plantas de pessegueiro, com $21 \%$ em relação à testemunha. Nas parcelas nas quais se cultivou nabo forrageiro, de modo geral, foram observados menores diâmetros do tronco e comprimento de ramos que aquelas nas quais se cultivou tremoço-azul e aveia-preta+chícharo (Tabela 1). Tais resultados do tremoço-azul, da aveia-preta+chícharo pode estar relacionado à característica de fixação biológica de nitrogênio ao solo realizada pelas leguminosas, como sugerido por CALEGARI (1999). Algumas leguminosas podem fixar o equivalente a $90 \mathrm{~kg} \cdot \mathrm{ha}^{-1}$ de nitrogênio. E o menor valor de diâmetro do tronco e comprimento de ramo, no caso do nabo forrageiro, provavelmente, pode estar relacionado a alguma forma de alelopatia desta cobertura vegetal à cultura do pessegueiro, pois ALMEIDA \& RODRIGUES (1985), em condições de bioteste, observaram que houve efeito alelopático do nabo forrageiro sobre o desenvolvimento de plantas de feijoeiro, milho e soja. ALPI et al. (2001) citaram que as substâncias ativas no processo de alelopatia das crucíferas, como o nabo forrageiro, são os glucosinatos - glucosídeos nos quais há enxofre.

Para o índice de fertilidade, observou-se maior número de pares de gemas floríferas por centímetro de ramo nas plantas de pessegueiro com cobertura de nabo forrageiro, seguidos dos tratamentos com nabo forrageiro+ervilha forrageira, aveiapreta+nabo forrageiro, aveia-preta+ervilha forrageira e chícaro (Figura 1). Isso deveu-se à diminuição do comprimento dos ramos das plantas de pessegueiro e ao encurtamento da distância dos entrenós pelo possível efeito alelopático do nabo forrageiro, já mencionado, conforme observado na Tabela 1. Tal fato já foi relatado por ALMEIDA \& RODRIGUES (1985); DERPSCH \& CALEGARI (1992), em culturas anuais. De acordo com DERPSCH (1984) e FIORIN (1999), o nabo forrageiro disponibiliza $101 \mathrm{~kg} . \mathrm{ha}^{-}$ ${ }^{1}$ de nitrogênio reciclado para o solo. Porém, neste estudo, não foi observado efeito aparente do nitrogênio disponibilizado pelo nabo forrageiro no desenvolvimento vegetativo das plantas de pessegueiro. Contrariamente, observou-se redução no comprimento de ramos e no diâmetro do tronco das plantas de pessegueiro.

A consorciação de aveia-preta + chícharo produziu quantidades superiores de massa verde e massa seca (Figura 2). Essa consorciação também propicia a fixação biológica de nitrogênio, através do chícharo e a manutenção da cobertura do solo por um período mais longo, pelo emprego da aveia, que possui elevada relação $\mathrm{C} / \mathrm{N}$. A combinação de aveia- preta + chícharo produz maior quantidade de massa fresca e seca, que ocasiona maior cobertura do solo e por período mais prolongado. 
TABELA 1 - Diâmetro do tronco, volume de copa e comprimento de ramo de plantas de pessegueiro, cultivar Maciel, conduzidas em Y, sob o sistema de Produção Integrada. FAEM/UFPel, Pelotas, 2004.

\begin{tabular}{|c|c|c|c|c|}
\hline Cobertura vegetal & $\begin{array}{c}\text { Diâmetro do tronco } \\
(\mathrm{cm})\end{array}$ & $\begin{array}{c}\text { Volume de copa } \\
\left(\mathrm{m}^{3}\right)\end{array}$ & $\begin{array}{l}\text { Comprime } \\
\text { de ramo (c }\end{array}$ & $\begin{array}{l}\text { iento } \\
\text { (cm) }\end{array}$ \\
\hline Aveia-preta & 23,11 abc & 0,36 a & 27,64 & \\
\hline Nabo forrageiro & $20,47 \quad \mathrm{c}$ & $0,32 \mathrm{ab}$ & 22,31 & $\mathrm{~b}$ \\
\hline Chícharo & 21,40 & $0,34 \mathrm{ab}$ & 25,19 & $a b$ \\
\hline Ervilha forrageira & 23,45 abc & 0,36 a & 27,72 & a \\
\hline Tremoço-azul & 26,35 a & 0,36 a & 27,94 & a \\
\hline Aveia-preta+ervilha forrageira & 24,41 abc & $0,32 \mathrm{ab}$ & 29,00 & a \\
\hline Aveia-preta+nabo forrageiro & 24,41 bc & $0,31 \mathrm{ab}$ & 27,87 & a \\
\hline Nabo forrageiro+ervilha forrageira & 22,89 abc & $0,32 \mathrm{ab}$ & 28,55 & $\mathrm{a}$ \\
\hline Aveia-preta+chícharo & $25,49 \mathrm{ab}$ & $0,33 \mathrm{ab}$ & 23,00 & b \\
\hline Testemunha & 23,42 abc & $0,30 \mathrm{~b}$ & 28,27 & $\mathrm{a}$ \\
\hline $\mathrm{CV} \%$ & 12,2 & 7,1 & 15,2 & \\
\hline
\end{tabular}

Médias seguidas por letras distintas diferem entre si, pelo teste de Duncan, ao nível de $5 \%$

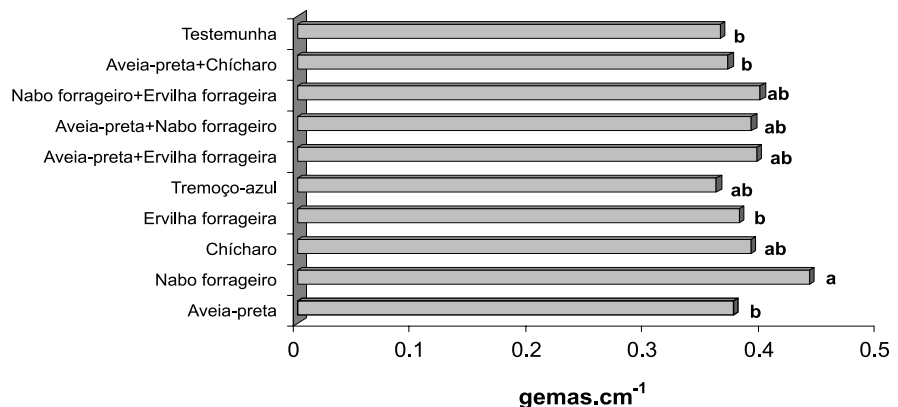

FIGURA 1 - Índice de fertilidade de ramos de pessegueiro cv. Maciel conduzido em Produção Integrada, sobre diferentes coberturas vegetais. FAEM/UFPel, Pelotas, 2004. Médias seguidas por letras distintas diferem entre si pelo teste de Duncan ao nível de $5 \%$.

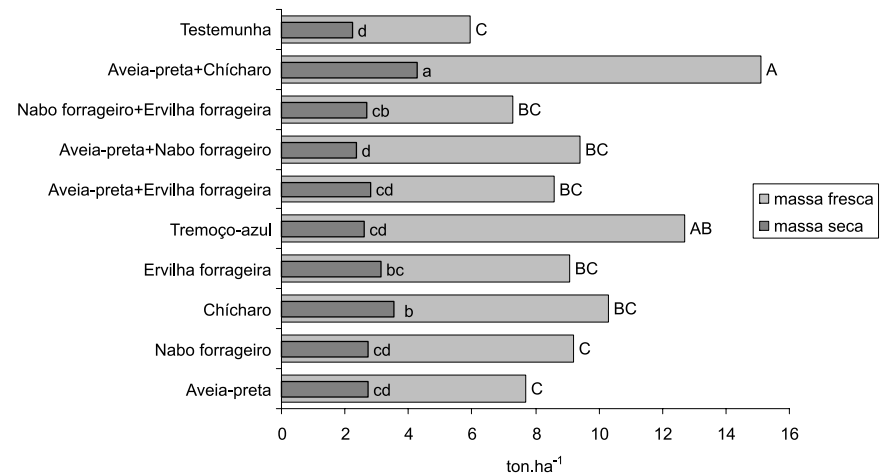

FIGURA 2 - Massa fresca e seca de coberturas vegetais de solo em pomar de pessegueiro cv. Maciel conduzido em Produção Integrada FAEM/UFPel, Pelotas, 2004. Médias seguidas por letras distintas diferem entre si, pelo teste de Duncan, ao nível de 5\%. Maiúsculas para massa fresca e minúsculas para massa seca.

Todas as espécies testadas apresentaram boa adaptação às condições de estudo, sendo que somente a ervilha forrageira apresentou alguns sintomas de oídio (Erysiphe poligoni DC), que, em consorciação com aveia, foram acentuados provavelmente devido ao microclima formado nas entrelinhas do pomar.

\section{CONCLUSÕES}

1. Todas as espécies de cobertura vegetal testadas adaptamse às condições edafoclimáticas da região Sul do Rio Grande do Sul.

2. O desenvolvimento vegetativo e o índice de fertilidade de gemas do pessegueiro são influenciados pelo cultivo de coberturas vegetais intercalares.

\section{AGRADECIMENTOS}

Agradecemos ao Dr. Luís Marcolina, da Estação Experimental do IAPAR - Pato Branco, pela disponibilização das sementes das coberturas vegetais utilizadas neste estudo; à família Costa Gomes, em especial ao finado Sr. Florentino, por disponibilizar sua propriedade para a execução dos experimentos; ao CNPq e à CAPES, pelo apoio financeiro.

\section{REFERÊNCIAS}

ALMEIDA, F.S.; RODRIGUES, B.N. Guia de herbicidas: contribuição para o uso adequado em plantio direto e convencional. Londrina: IAPAR, 1985. p.341-399.

ALPI, A.; PUPILLO, P.; RIGANO, C. Fisiologia delle piante. $3^{\text {rd }}$ ed. Napoli: EdiSES, 2001. 560p.

CALEGARI, A. Rotación de cultivos en el sistema de siembra directa. In: PAULETTI, V. SEGANFREDO, R. Plantio direto: atualização tecnológica. São Paulo: Fundação Cargill, 1999. 171p.

DERPSCH, R. Alguns resultados sobre adubação verde no Paraná. In: ADUBAÇÃO verde no Brasil. Campinas: Fundação Cargill, 1984. p. 268-279.

DERPSCH, R.; CALEGARI, A. Plantas para adubação verde de inverno. Londrina: IAPAR, 1992. 80p. (Circular, 73)

FACHINELLO, J.C.; COUTINHO, E.F.; MARODIN, G.A.B.; BOTTON, M.; DE MIO, L.L.M. Normas técnicas e documentos de acompanhamento da produção integrada de pêssego. Pelotas: UFPel/FAEM, 2003. 92p.

FIORIN, J.E. Plantas recuperadoras da fertilidade do solo. In: CURSO SOBRE ASPECTOS BÁSICOS DE FERTILIDADE E MICROBIOLOGIA DO SOLO EM PLANTIO DIRETO FERTILIDADE DO SOLO EM PLANTIO DIRETO, 1999, Cruz Alta. Resumos... Passo Fundo: Ed. Aldeia Norte, 1999. p. 39-55.

GIOVANNINI, D. et al. Esperienze di conduzione del terreno in un pescheto biologico. Rivista di Frutticoltura e di Ortofloricoltura, Bologna, v.1, p. 21-29, 2001.

MARANGONI, B.; SCUDELLARI, D.; TACLIAVINI, M. Relazione tra nutrizione azotata e metabolismo delle piante. Rivista di Frutticoltura e di Ortofloricoltura, Bologna, v.57, p.7-8, 1995.

MONEGAT, C. Plantas de cobertura do solo: características e manejo em pequenas propriedades. Chapecó: Ed. do Autor, 1991.337p. 